\title{
Influences of high-reflective mulching membrane coupled with a drip sub-irrigation system on temperature and humidity of the soil
}

\author{
Alessia Di Giuseppe ${ }^{1, *}$, Mattia Manni $^{1}$, Alessandro Petrozzi ${ }^{1}$, Laura Maria Becchetti $^{1}$, \\ Beatrice Castellani ${ }^{1,2}$, Andrea Nicolini ${ }^{1,2}$, Federico Rossi ${ }^{1,2}$, and Franco Cotana ${ }^{1,2}$ \\ ${ }^{1}$ CIRIAF, Interuniversity Research Centre on Pollution and Environment "M. Felli", Via G. Duranti \\ 67, 06125, Perugia, Italy \\ ${ }^{2}$ University of Perugia, Department of Engineering, Via G. Duranti 93, 06125, Perugia, Italy
}

\begin{abstract}
The present study deals with an original application of RR materials to the agriculture sector, evaluating the effectiveness of a highreflective mulching membrane treated with glass micro-spheres and coupled with a drip sub-irrigation system. An experimental facility, in which this technology is exploited, has been set up in Perugia (Italy). Influences of the mulching membrane on hygrothermal properties of the soil were evaluated through humidity and temperature sensors during the monitoring campaign. Data from unmulched field section was used as a reference case. The effectiveness of this technology was evaluated by focusing on three days that are representative of as much weather conditions. The monitoring campaign conducted from April to May 2021 has demonstrated that the high-reflective mulching membrane can reduce the temperature and relative humidity fluctuations throughout the day. In addition, the mulching membrane can reduce the soil temperature at different depths (i.e. $0.05 \mathrm{~m}, 0.10 \mathrm{~m}$, and $0.15 \mathrm{~m}$ ). The highest soil temperature reduction was found equal to $8.95^{\circ} \mathrm{C}$ at $0.15 \mathrm{~m}$. Basing on such preliminary results, a more detailed and extended monitoring campaign will be performed in summer conditions.
\end{abstract}

\section{Introduction}

Increasing urbanization process is significantly contributing to global warming [1]. The most recent census has found that around $54 \%$ of the global population is currently living in cities, and such amount is expected to reach $68 \%$ by 2050 [2]. The consequent densification and urban sprawl imply the increase of the anthropogenic heat as well as the reduction of permeable and vegetated surfaces [3,4]. Urban artificial surface and layout, climate conditions and meteorological factors, together with the increase of the anthropogenic

\footnotetext{
* Corresponding author: alessia.digiuseppe@,crbnet.it
} 
heating are the main causes of the Urban Heat Island (UHI) phenomenon which represents one of the most investigated urban phenomena.

In the last years, numerous research studies have been focusing on the development of technologies and strategies aiming at improving urban micro-climate conditions, while mitigating UHI effects and urban overheating. Exploiting materials characterized by high solar reflectance index (SRI) as urban coatings has been largely recognized as an effective strategy to tackle the raising of the air temperature within the city [5-7]. In fact, lowering the absorbed fraction of solar irradiance contributes to generating cool oases. Among the investigated solutions, retro-reflective (RR) materials, which are usually employed in street signs to enhance their night-time visibility, have been recently proposed as building coatings. Such materials are widely appreciated in the building sector due to their ability to reflect backwards most of the incident solar radiation, thus reducing the energy absorbed and stored into the urban canyons through multiple inter-building reflections [8,9]. In fact, RR materials are high SRI coatings which present considerably lower surface temperature than traditional construction materials $[10,11]$.

Within this framework, the present study aims at proposing an original application of $\mathrm{RR}$ materials to the agriculture sector and urban greeneries. It consists of a mulching membrane in which the top face is treated with a high-reflective white painting enhanced with embedded glass microspheres, while a system for drip sub-irrigation is implemented on the bottom face. The innovation with respect to state of the art is given by the advanced optic property (high-reflective and retro-reflective) of the proposed mulching membrane. In addition to the already proven advantages given by the commonly mulching membranes which are widely employed in the agricultural sector in food crops grown [12-14], i.e. influencing plant growth, development and crop's yield and fruits' size, the innovative high reflective mulching membrane could also be able to minimize the consumption of natural resources as well as mitigating the global overwarming. It allows reducing the temperature of the ground below with a decrease of the evapotranspiration losses. Moreover, its low permeability to water makes it suitable to be integrated with a rainwater recovery system to reduce water consumption for irrigation. These improvements together with the increasing of reflected solar irradiation contribute to creating a favorable environment for the crops.

Thus, the proposed technology has a direct impact on the increase of the reflected solar irradiation amount (i.e. albedo), on the food production (i.e. growth rate and yield of food crops), and on water use optimization. In a preliminary analysis presented in Manni et al. [15] highlighted that the high-reflective mulching membrane was capable of enhancing the ground solar reflectance by up to 0.60 , increasing the productivity of tomato crop by more than $20 \%$, and saving $90 \%$ of the consumed water. Also, the influences on phenological development were assessed demonstrating that crops mulched produced fruits earlier than unmulched crops [15]. The high-reflective membrane has been patented as "High-albedo membrane for the mitigation of the global warming, for the mulching, and for the subirrigation" (the original Italian title is "Membrana ad elevato albedo per la mitigazione del riscaldamento globale, per la pacciamatura e la subirrigazione", number 202018000003874), and both a laboratory-scale prototype and a small-scale experimental field have been designed and implemented in the Central Italy.

The soil mulching can be performed with organic materials (i.e. straw) or with inorganic materials (i.e. plastic films) which exhibit different behavior in terms of soil temperature and soil moisture. The effect of different mulching materials on the soil properties has been largely investigated in Literature: in Sinkeviciene et al. [16], the reduction in soil temperature as a result of organic mulching ranging from $0.7^{\circ} \mathrm{C}$ to $1.6^{\circ} \mathrm{C}$; in the study of Kosterna [13], the straw mulching resulted in the reduction of soil temperature at a depth of $0.10 \mathrm{~m}$ equal to $2.1^{\circ} \mathrm{C}$ and $5.5^{\circ} \mathrm{C}$ in the morning and in the afternoon respectively. In Mendonça et al. [12], soil mulching with dark-colored plastic films contributed to increase 
the soil temperature with an average increment of $2.27-2.55^{\circ} \mathrm{C}$ and $4^{\circ} \mathrm{C}$ at 7 a.m. and 2 p.m. respectively in the spring-summer season. Similar behavior was observed in Majumder et al. [17] and Zhang et al. [18]. Finally, in Schonbeck et Evanylo [19], the effects of organic and plastic mulches on soil temperature and soil moisture were investigated. Organic mulches contributed to slower soil warming and exhibited the highest soil moisture content, while black plastic mulches increased the soil temperatures and resulted in lower soil moisture levels.

No study regarding the effect of mulch films coupled with an irrigation system, on soil temperature and moisture content, was found in Literature.

The current research aimed to determine the effects of this technology in terms of soil moisture, soil temperature at three different depths as well as the surface temperature at the top and bottom face of the mulching membrane, comparing to a control plot without mulch.

The monitoring campaign was carried out from April to May 2021 in the experimental field in Perugia. The main research domain covered by this work concerns (i) the set-up and the test of the mulching membrane technology on a laboratory-scale prototype, (ii) the setup of the experimental field and the design of the sensors layout, and (iii) data assessment.

\section{Methodology}

This research was organized in four main stages: (i) set-up and testing of the laboratoryscale prototype, (ii) set-up of the experimental field, (iii) monitoring campaign, (iv) data post-processing and data assessment.

In the first stage, the high-reflective mulching membrane was tested through a laboratory-scale prototype in the CIRIAF center (Figure 1). Two different configurations were simulated: the soil covered by the mulching membrane (enhanced configuration) and the unmulched soil (reference case). The surface temperature of the soil was monitored in both the scenarios to preliminary evaluate the effectiveness of the high-reflective membrane. The solar source was simulated through a lamp, while the effects of the atmosphere were simulated by two glazed hemispheres placed between the soil and the lamp.

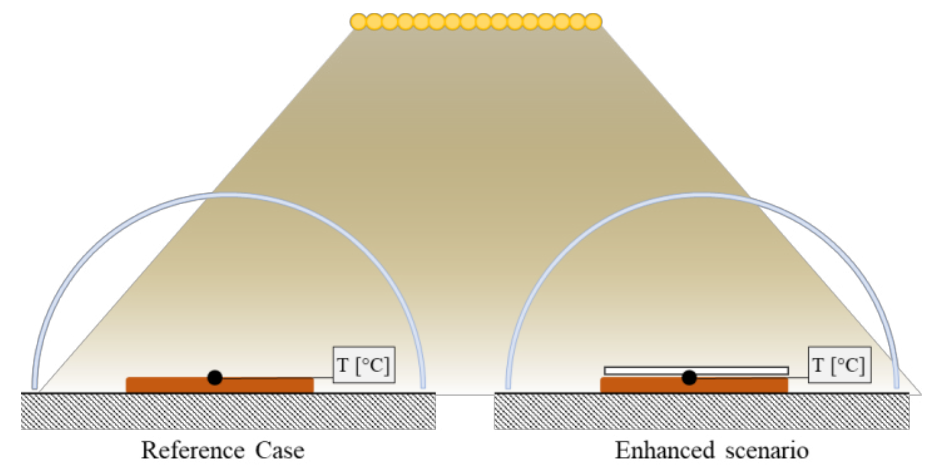

Fig. 1. Laboratory-scale prototype in the CIRIAF.

The core of the second stage is represented by the application of the high-reflective mulching membrane to a $100 \mathrm{~m}^{2}$ large experimental field in Perugia.

As in the stage one, two scenarios were investigated in the experimental field by dividing this in two sections: the high-reflective mulching membrane coupled to the drip sub-irrigation system were implemented on the first, while a traditional drip irrigation system was applied to the second. The two sections of the experimental field were equipped 
with sensors to monitor: (i) the relative humidity of the soil surface, (ii) the surface temperature of both the soil and the membrane, and (iii) the temperature values at various soil depths. In addition, the temperature at the bottom face of the mulching membrane was measured in the mulched field section.

In the third stage, the monitoring campaign was performed from April to May 2021. In the unmulched section, the soil temperature was measured at surface level and at $0.05 \mathrm{~m}$, $0.10 \mathrm{~m}$, and $0.15 \mathrm{~m}$ deep, while in the enhanced configuration the temperatures at the top and the bottom membrane surfaces were performed in addition to the temperature measurements carried out at the aforementioned soil depths. Furthermore, the relative humidity of the soil surface was assessed. In the enhanced configuration, the humidity sensor was placed between the soil and the membrane, while in the reference case it laid on the soil surface. These parameters were monitored with a two-minute time-step. In addition, data concerning air temperature $\left({ }^{\circ} \mathrm{C}\right)$, and relative humidity $(\%)$ were collected during the monitoring campaign, and then used in the fourth stage of the applied method.

The fourth stage focused on the data post-processing and data analysis. Starting from the environmental monitoring data (Figure 2), three representative days with (i) the lowest daily air temperature, (ii) the highest daily air temperature, and (iii) the mean daily air temperature, respectively, were selected in order to evaluate the effects of the enhanced configuration in different weather conditions.

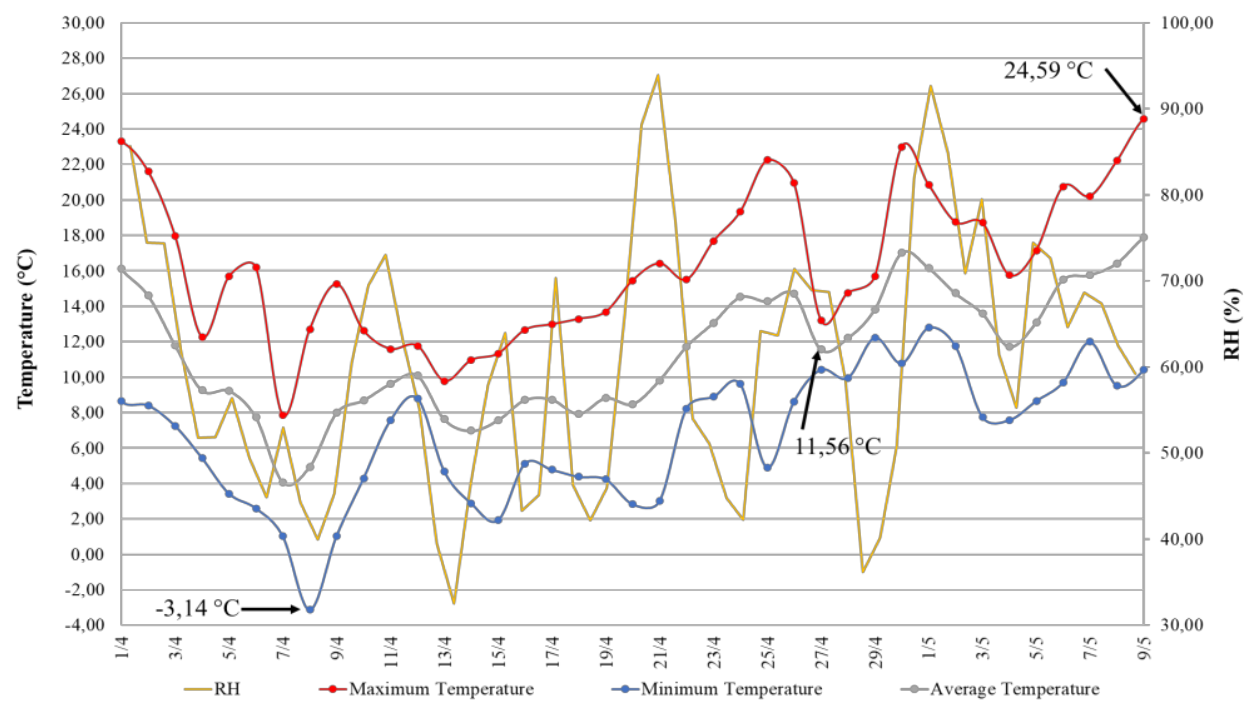

Fig. 2. Daily relative humidity, maximum, minimum, and average temperature during the monitoring campaign in Perugia.

Thus, according to the Figure 2, the representative days selected among the monitored period for the purpose of this study were: (i) the $8^{\text {th }}$ of April which exhibited the minimum daily air temperature $\left(-3.14^{\circ} \mathrm{C}\right.$ at 6 a.m.), (ii) the $9^{\text {th }}$ of May which presented the maximum daily air temperature $\left(24.59^{\circ} \mathrm{C}\right.$ at 3 p.m.), and (iii) the $27^{\text {th }}$ of April showing the mean daily air temperature $\left(11.56^{\circ} \mathrm{C}\right.$ at 5 p.m. $)$.

Then, the hourly mean value was calculated for each monitored parameter in the three selected days, and a comparative analysis was carried out. 


\subsection{Laboratory-scale prototype}

The laboratory-scale prototype was realized at CIRIAF center (Figure 3a) and it consisted of:

i. the solar lamp, that simulates the solar source;

ii. two glazed hemispheres for reproducing the effects of the atmosphere on the radiation reflected by the ground;

iii. the two investigated soil configurations corresponding to the reference case and the enhanced scenario;

iv. two sensors measuring the soil surface temperature.

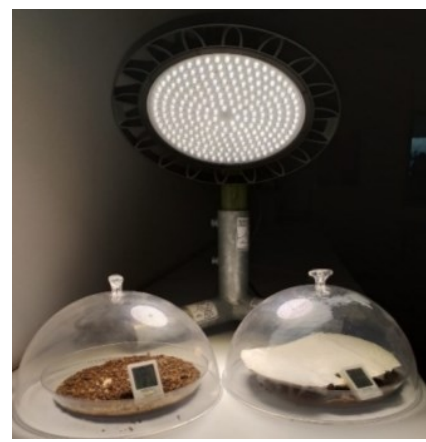

(a)

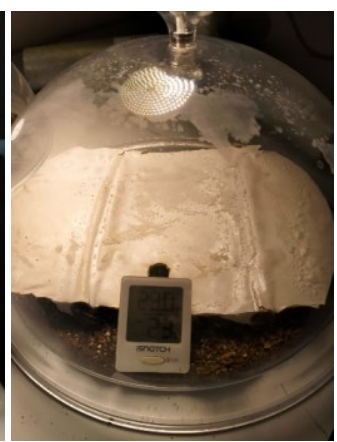

(b)

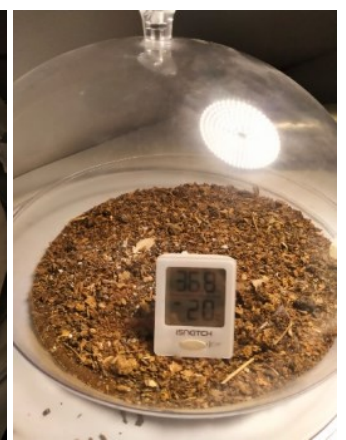

(c)

Fig. 3. Experimental pre set-up at the CIRIAF laboratory.

When the equilibrium state of the system was achieved, the soil temperatures were stationary and converged to two different values. The highest corresponded to the unmulched soil and it was as high as $36.8^{\circ} \mathrm{C}$ (Figure $3 \mathrm{~b}$ ). On the other hand, the soil covered by the high-reflective mulching membrane prototype barely reached a temperature level of $29.0^{\circ} \mathrm{C}$ (Figure 3c).

\subsection{Experimental field}

The experimental field was almost $100 \mathrm{~m}^{2}$ large and it was realized in the Engineering University Campus in Perugia, Italy (43 $7^{\prime} 10.061^{\prime \prime} \mathrm{N}, 12^{\circ} 21^{\prime} 25.583^{\prime \prime}$ E) (Figure 4).

The experimental field consisted of 14 rows: up to 12 were covered by the highreflective mulching membrane and they represented the enhanced configuration to be compared with the other reference rows (unmulched section). The innovative mulching membrane was treated with a high-reflective painting enhanced with embedded glass microspheres on the top surface to implement a retro-reflective behavior. A sub-irrigation system is implemented on the bottom face of the mulching membrane. A conventional drip irrigation system (without the mulching membrane) was installed in the reference configuration. The geometry properties of the field together with the water-resistance feature of the membrane permit rainwater to be recovered into a 5,000 1 tank during the precipitation events. Such a water volume can be used for irrigation to reduce the exploitation of water from the aquifer. 
a)

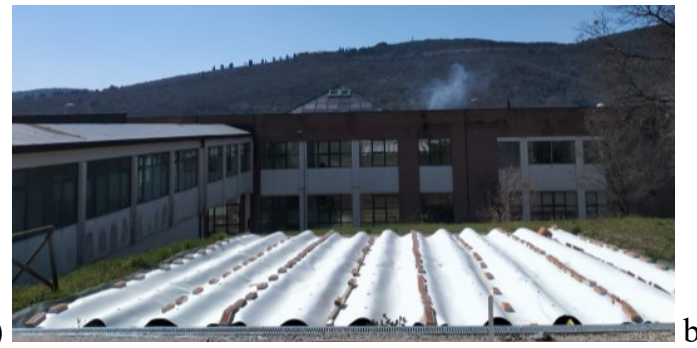

b)

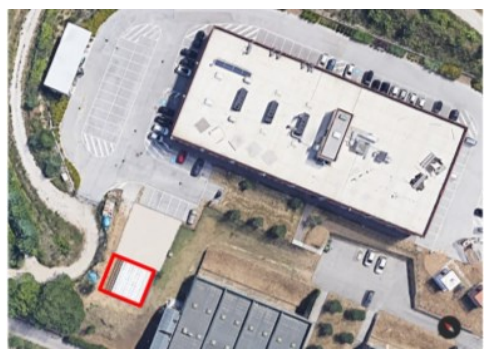

Fig. 4. A picture of the experimental field in the Engineering University Campus in Perugia (a) and an aerial view of the case-study location with the shape of the experimental field evidenced in red (b).

\subsection{Analytical methods}

To test the cooling potential of the high-reflective mulching membrane, a monitoring campaign was carried out from the $1^{\text {th }}$ of April to $9^{\text {th }}$ of May 2021. Therefore, the effect of this technology on the soil temperature and soil moisture was investigated.

The temperature at the membrane surface (both the top and bottom face) and at different soil depths was measured through type $\mathrm{T}$ thermocouples. Thermocouples were connected to a Lutron BTM-4208SD data logger recording the temperature values with a two-minute time-step.

Soil temperature values were collected by thermocouples buried into the soil at three different depths: (i) $0.05 \mathrm{~m}$ below the soil surface, (iii) $0.10 \mathrm{~m}$ below the ground, and (iii) $0.15 \mathrm{~m}$ below the soil. In Figure 5, the monitoring soil temperature at $0.10 \mathrm{~m}$ below the ground in the mulched field section was shown.

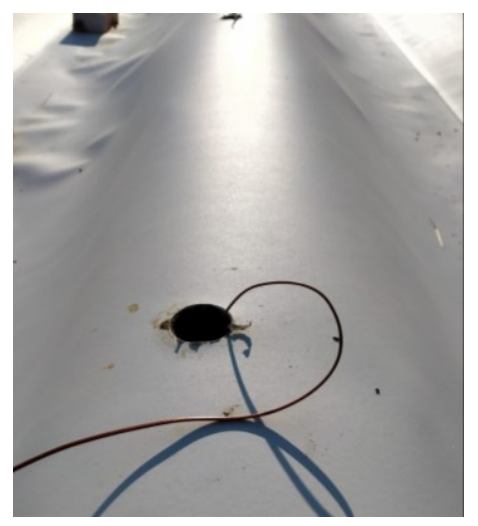

Fig. 5. Thermocouple buried into the soil at $0.10 \mathrm{~m}$ below the ground in the mulched field section.

As far as the surface is concerned, when the surface is covered by the high-reflective mulching membrane, two thermocouples are placed above and below it, respectively. In the reference scenario, the thermocouple lays on the ground. Both the thermocouples directly exposed to the sunlight were covered by an insulating layer (Figures 6a and 6b) to avoid potential biases due to the exposition of thermocouples to solar irradiation. 
a)
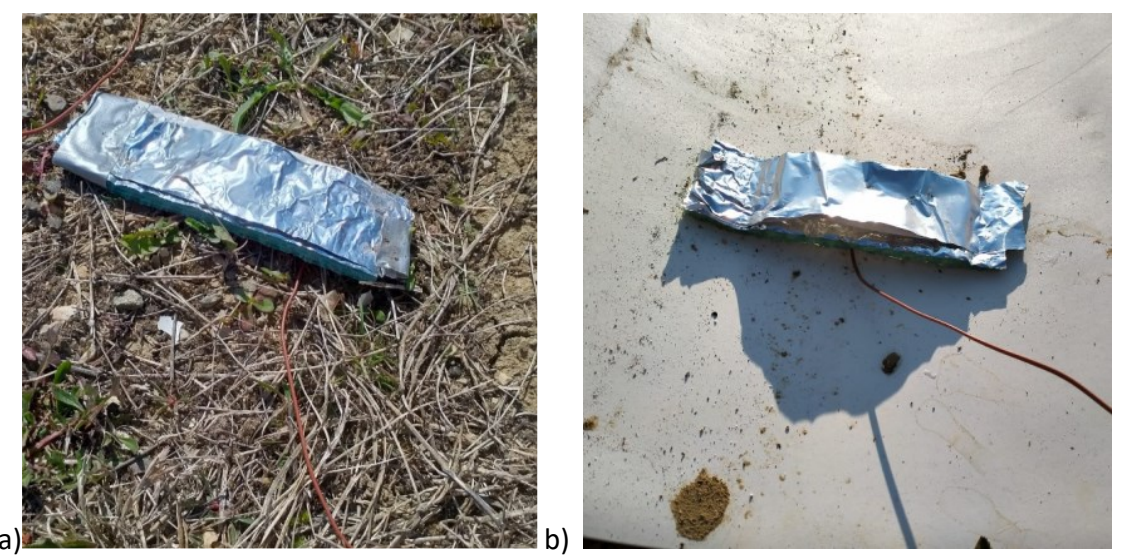

Fig. 6. Thermocouples at the ground level (Figure 6a) and at the membrane side top (Figure 6b).

Two EasyLog USB data logger were utilized to monitor the soil moisture, considered as the relative humidity at ground level. The sensor was installed just above the ground level in the unmulched section, and between the ground and the membrane in the field section covered by the mulching membrane.

The monitoring campaign was conducted in the two field configurations. Data from unmulched field section was used as a reference case. Then, the effectiveness of the proposed technology was evaluated by comparing the results from the two sections of the field for the $8^{\text {th }}$ and $27^{\text {th }}$ of April, and for the $9^{\text {th }}$ of May, according to the methodology described above.

Environmental monitoring was performed through a fixed weather station settled at the rooftops level in the CIRIAF building. Data concerning air temperature $\left({ }^{\circ} \mathrm{C}\right)$, and relative humidity (\%) were collected during the monitoring campaign, and then used in the data post-processing stage.

\section{Results}

\subsection{Effects of mulching membrane on Soil Temperature at different air temperature conditions}

Data concerning the soil temperature at different depths for the three representative days of different weather conditions, were reported in the Figures 7, 8, and 9 below. 
20,00

8th of April 2021

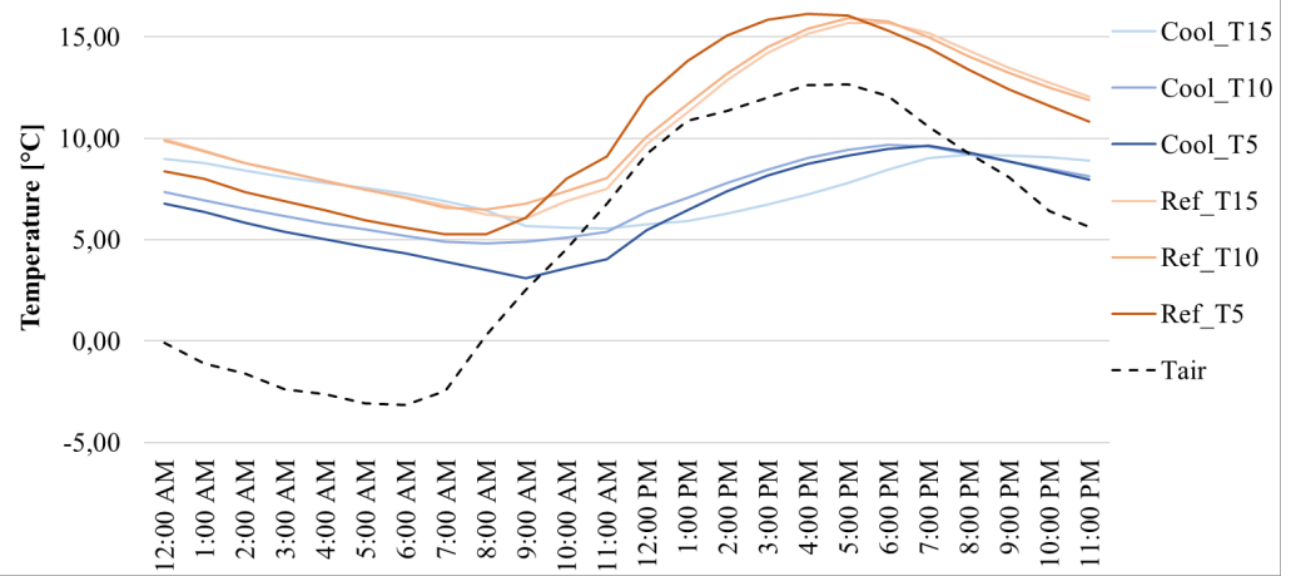

Fig. 7. Temperature monitored values at different soil depths for the two filed sections on the day exhibiting the minimum air temperature recorded value.

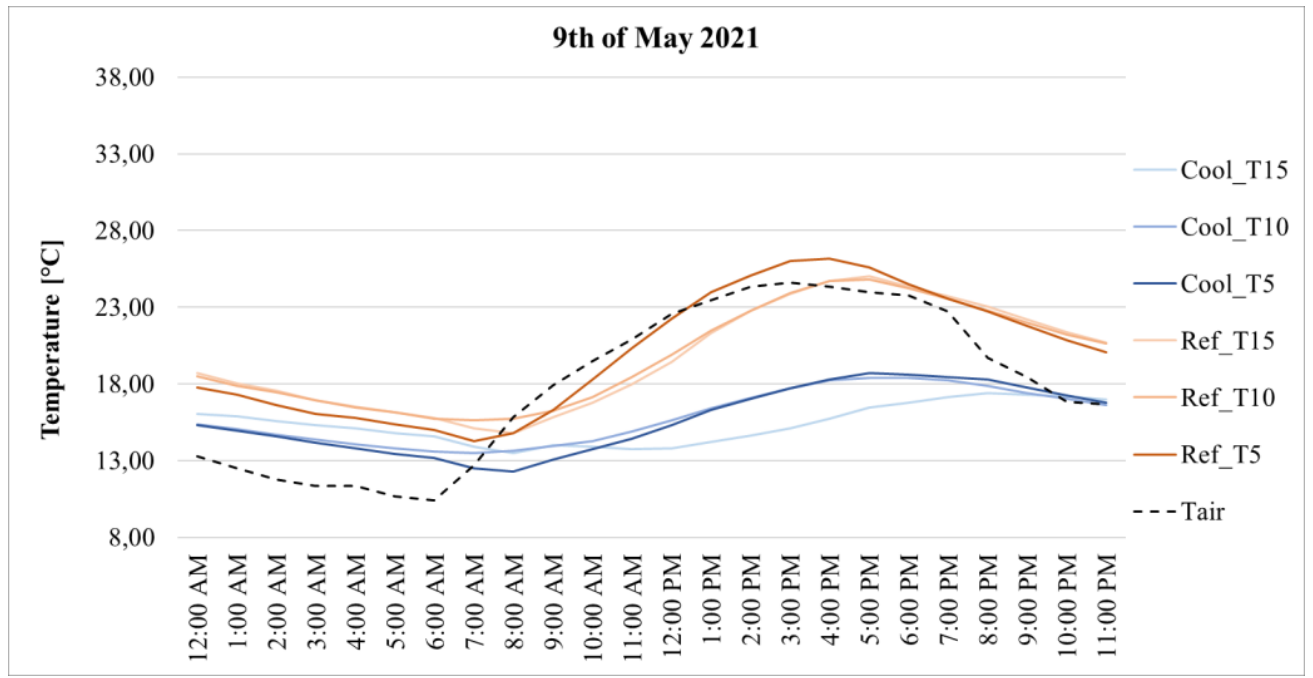

Fig. 8. Temperature monitored values at different soil depths for the two filed sections on the day exhibiting the maximum air temperature recorded value. 


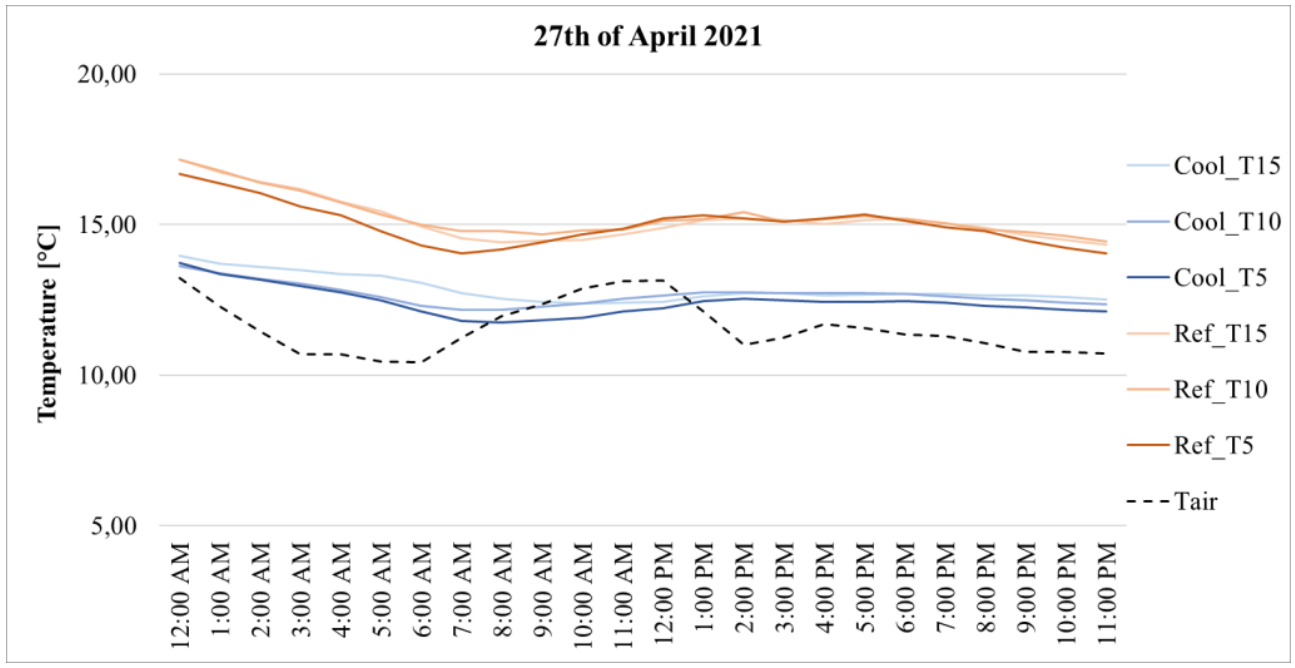

Fig. 9. Temperature monitored values at different soil depths for the two filed sections on the day exhibiting the mean air temperature recorded value.

The soil temperature values (throughout all the investigated depths) were lower in the configuration enhanced with the mulching membrane than in the section without that in all three selected days. The soil temperature followed a sinusoidal trend whose upper and lower limits varied according with the depth. The sinusoidal trend was more pronounced on the $8^{\text {th }}$ of April and on the $9^{\text {th }}$ of May, in which the air temperature ranged from $-3^{\circ} \mathrm{C}$ to $13^{\circ} \mathrm{C}$ on average and from $10^{\circ} \mathrm{C}$ to $25^{\circ} \mathrm{C}$ on average, respectively. On the contrary, the trend was less evident on the $27^{\text {th }}$ of April when air temperature varied from $10^{\circ} \mathrm{C}$ to $13^{\circ} \mathrm{C}$.

In Figures 10, 11, and 12 below, data concerning the surface temperature of the soil and the membrane for the three representative days, were reported:

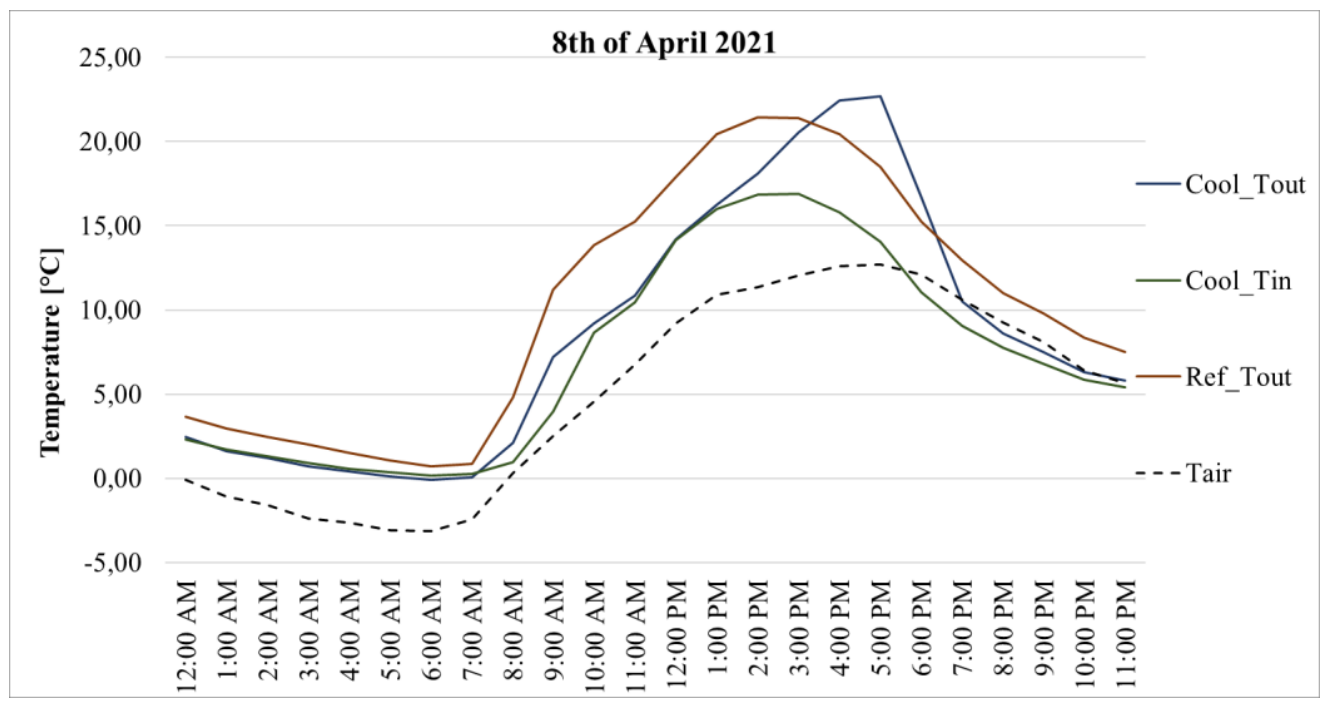

Fig. 10. The enhanced scenario's membrane side top and bottom temperature and the reference case's ground temperature on the day exhibiting the minimum air temperature recorded value. 


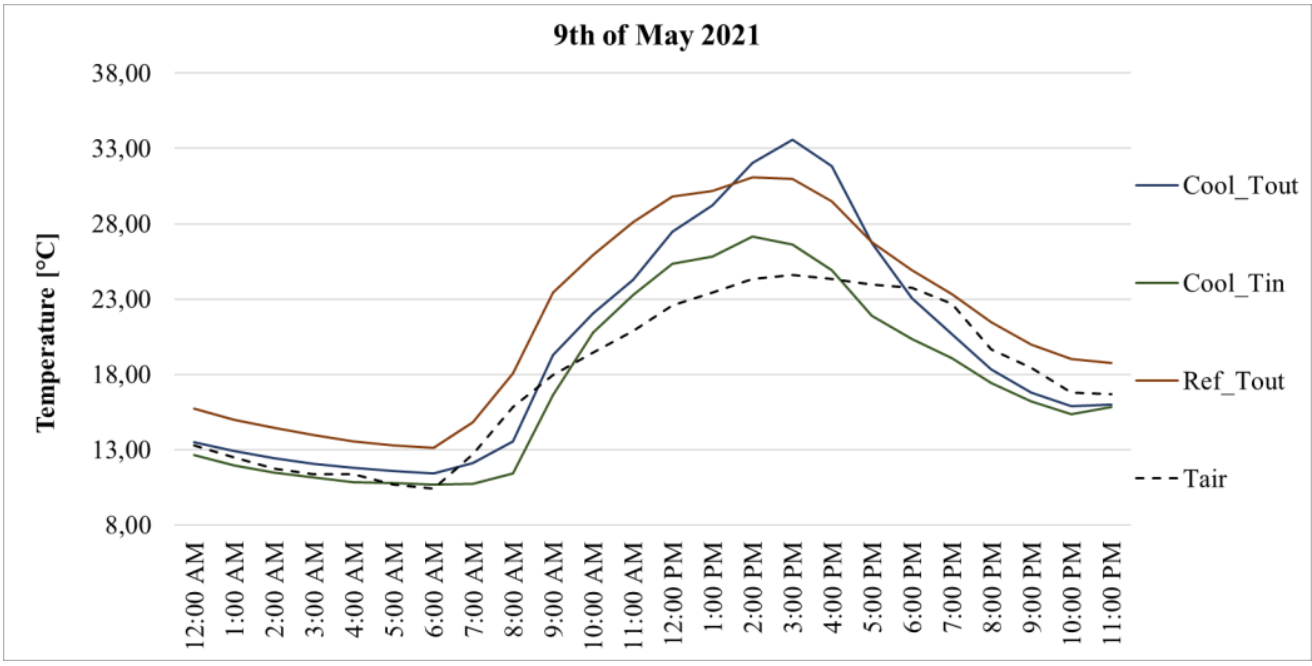

Fig. 11. The enhanced scenario's membrane side top and bottom temperature and the reference case's ground temperature on the day exhibiting the maximum air temperature recorded value.

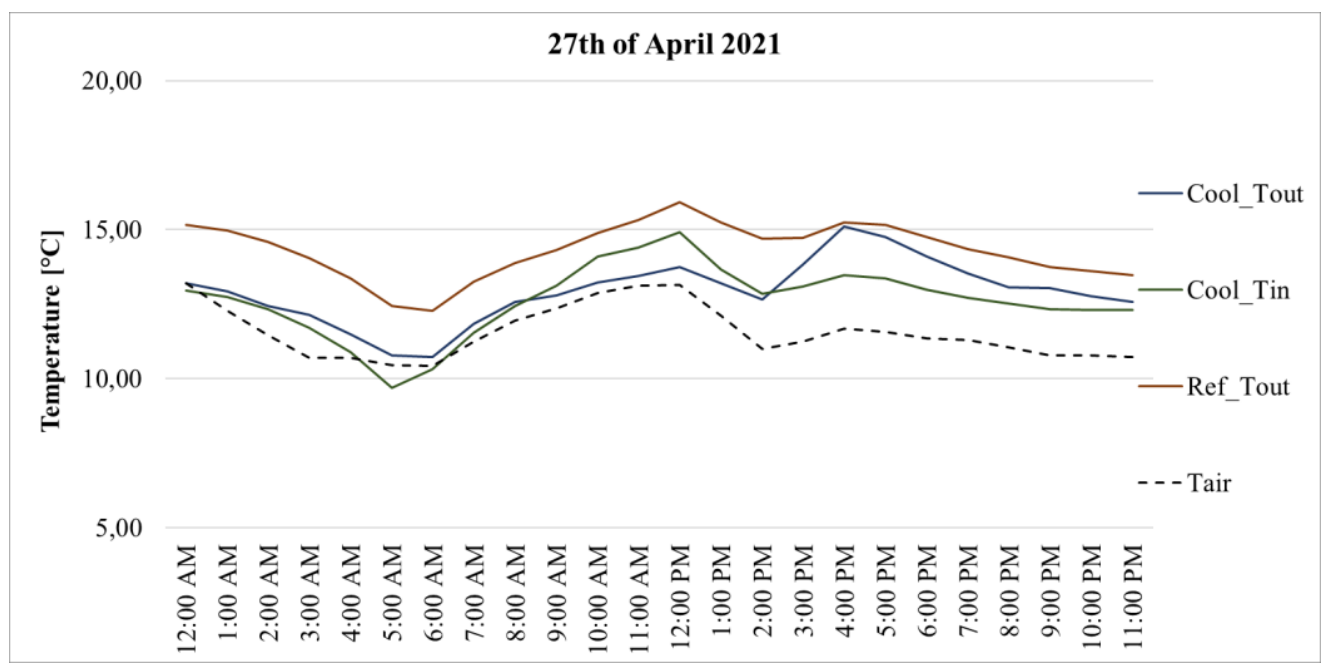

Fig. 12. The enhanced scenario's membrane side top and bottom temperature and the reference case's ground temperature on the day exhibiting the mean air temperature recorded value.

The mulching membrane surface temperature at the top side showed higher temperature fluctuations than temperature at ground level in the unmulched soil for the $8^{\text {th }}$ of April and the $9^{\text {th }}$ of May. This effect can be addressed to the latent heat of the moisture contained in the soil which was more than the one proper of the membrane. In particular, the mulching membrane temperature exhibited higher temperature than unmulched soil in the afternoon (from 4 p.m. to 6 p.m.) with the peaks mostly at 4 p.m. on the $8^{\text {th }}$ of April, while it showed higher temperature than unmulched soil during warmest hours of the day (from 2 p.m. to 4 p.m.) with the peaks mostly at 3 p.m. on the $9^{\text {th }}$ of May. On the other hand, the mulching membrane showed always lower temperature values with respect to the reference case on the $27^{\text {th }}$ of April. Nonetheless, the membrane surface temperature at the bottom side showed always the lowest values in comparison with the reference case's ground surface for all three representative days. 


\subsection{Effects of mulching membrane on Soil Moisture at different air temperature conditions}

The soil moisture (relative humidity at the ground level) from both the enhanced scenario and the reference case varied according to the fluctuations of the air relative humidity, although they exhibited highest values (Figures 13,14, and 15). The only exception to that was visible from 9 a.m. to 1 p.m. on the $9^{\text {th }}$ of May.

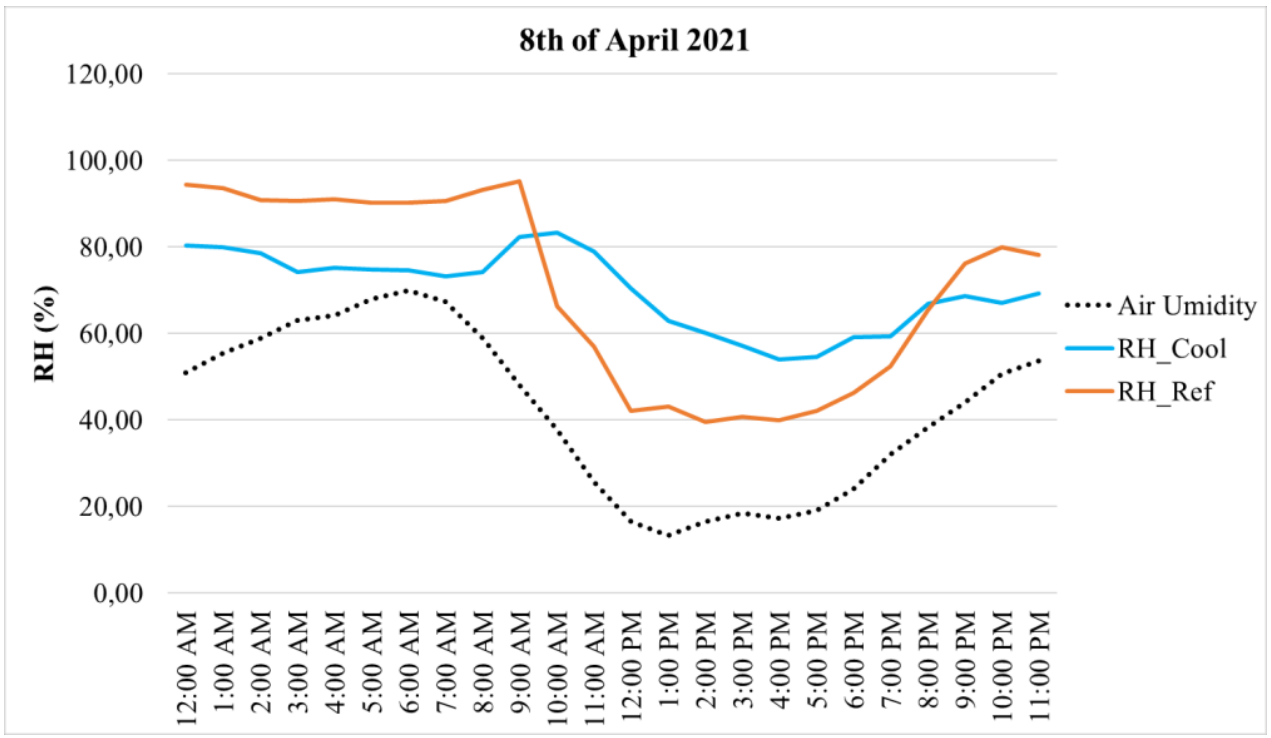

Fig. 13. Relative humidity (\%) in enhanced scenario (RH Cool) and in the reference case (RH Ref) on the day exhibiting the minimum air temperature recorded value.

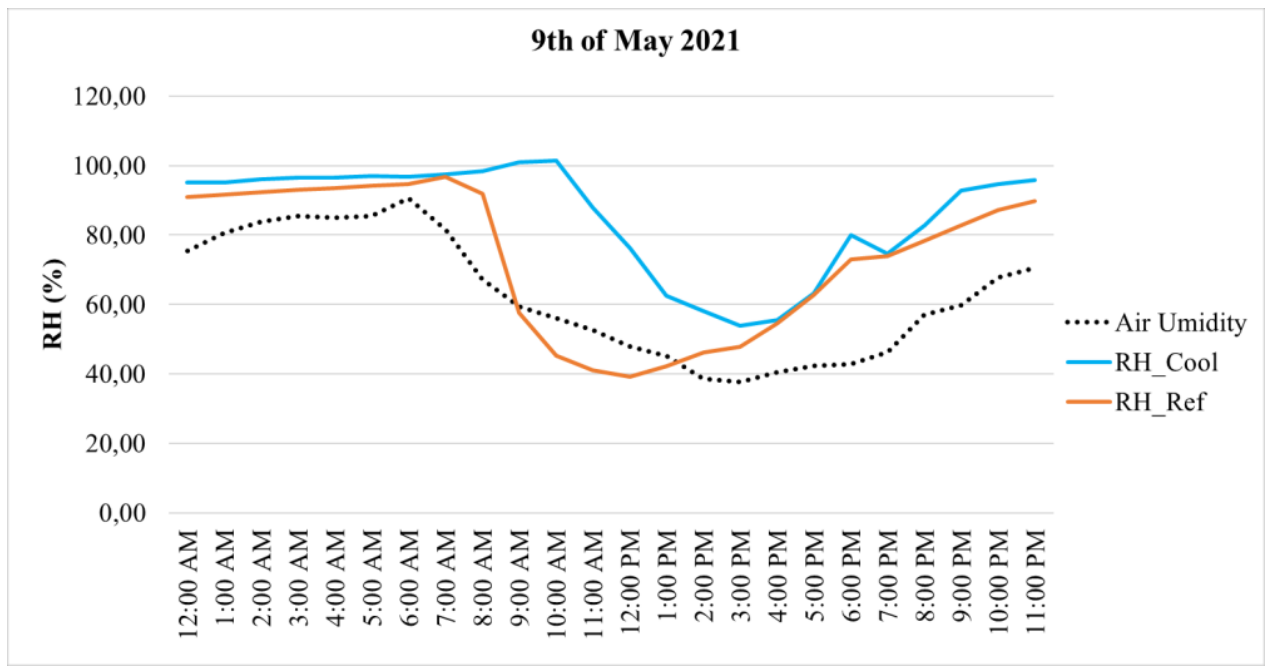

Fig. 14. Relative humidity (\%) in enhanced scenario (RH_Cool) and in the reference case (RH_Ref) on the day exhibiting the maximum air temperature recorded value. 


\section{7th of April 2021}

\section{0,00}

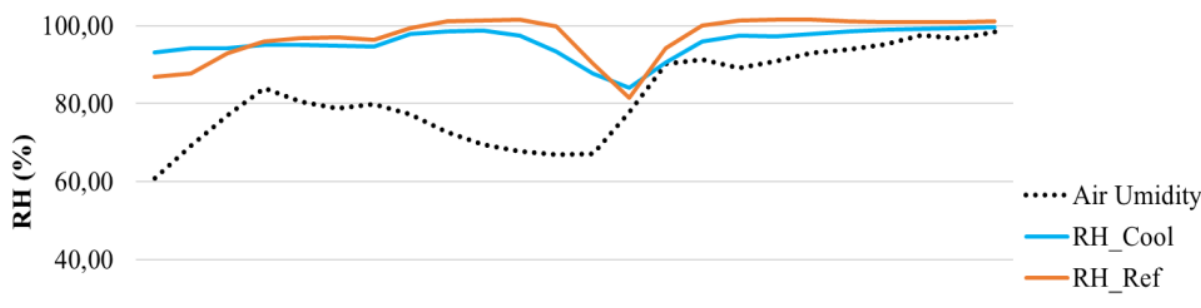

20,00

0,00

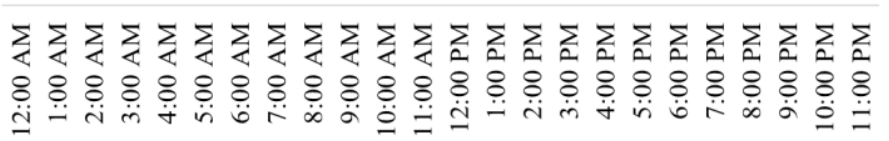

Fig. 15. Relative humidity (\%) in enhanced scenario (RH_Cool) and in the reference case (RH_Ref) on the day exhibiting the mean air temperature recorded value.

Relative humidity at the ground level was always higher below the mulching membrane (RH_Cool) than in the other section (RH_Ref) on the $9^{\text {th }}$ of May. On the $8^{\text {th }}$ of April RH_Cool showed the highest values from 10 a.m. to 8 p.m., while on the $27^{\text {th }}$ of April, RH_Cool and RH_Ref exhibited the same fluctuations during the day. Monitored values below the mulching membrane fluctuated from $60 \%$ to $80 \%$ throughout the $8^{\text {th }}$ of April, from $60 \%$ to $100 \%$ on the $9^{\text {th }}$ of May, and from $80 \%$ to $100 \%$ on the $27^{\text {th }}$ of April. In addition to that, the mulching membrane was found capable of reducing relative humidity variation throughout the day if compared to the reference case in which the RH_Ref ranged from $40 \%$ to $95 \%$ on the $8^{\text {th }}$ of April, and from $40 \%$ to $96 \%$ on the $9^{\text {th }}$ of May.

\section{Discussion}

For each monitored soil depth, the $\Delta \mathrm{T}$ values, defined as the difference between the enhanced scenario's soil temperature and the reference case's soil temperature, were shown in Figure 16 in which the terms "min", "average", and "max" were referred to the $8^{\text {th }}$ and $27^{\text {th }}$ of April, and the $9^{\text {th }}$ of May, respectively. 


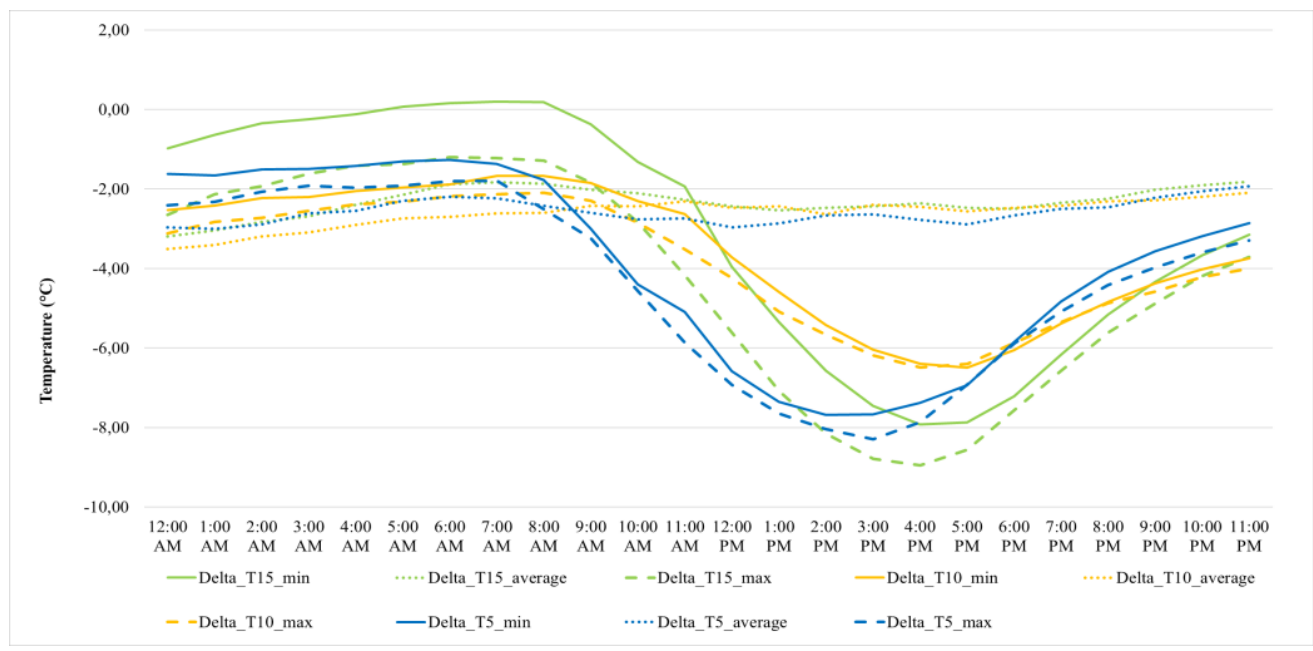

Fig. 16. Temperature differences between the enhanced scenario and the reference case for each investigated soil depth.

The highest $\Delta \mathrm{T}$ value for the $8^{\text {th }}$ of April was equal to $7.92^{\circ} \mathrm{C}$ (at $4: 00$ p.m.) at a depth of $0.15 \mathrm{~m}$, to $6.50{ }^{\circ} \mathrm{C}$ (at 5:00 p.m.) at a depth of $0.10 \mathrm{~m}$, and to $7.69{ }^{\circ} \mathrm{C}$ (at 2:00 p.m.) at a depth of $0.05 \mathrm{~m}$. For the $27^{\text {th }}$ of April, the highest $\Delta \mathrm{T}$ value was equal to $3^{\circ} \mathrm{C}$ on average from 12 a.m. to 1 a.m. at all investigated depths. Finally, for the $9^{\text {th }}$ of May, the reduction in soil temperature was averagely as high as $8.95^{\circ} \mathrm{C}$ (at 4 p.m.) at $0.15 \mathrm{~m}$ below the ground surface, while when it came to the depths of $0.10 \mathrm{~m}$ and of $0.05 \mathrm{~m}$, the $\Delta \mathrm{T}$ values were equal to $6.50^{\circ} \mathrm{C}$ at 4 p.m. and to $8.30^{\circ} \mathrm{C}$ at 3 p.m. respectively.

According to Pramanik et al. [20], the soil temperature is affected by the specific thermal properties and the color of the mulching material used. In fact, the color of the plastic mulch film determines the behavior of the incident solar radiation, affecting the soil profile temperature. Thus, dark-colored plastic mulching films resulted in an increase in soil temperature $[12,19]$, while the technology presented in this study, exhibited a reduction in soil temperature at all investigated depths.

The white mulching membrane here presented showed always a reduction in soil temperature similar to that performed in [13] and higher than the results obtained in Sinkeviciene et al. [16].

For both the temperatures monitored above and below the mulching membrane, the $\Delta \mathrm{T}$ values, defined as the difference between the enhanced scenario's membrane surface temperature and the reference case's ground temperature, were calculated by comparison with the ground temperature in the unmulched section in Figure 17 in which the terms "min", "average", and "max" were referred to the $8^{\text {th }}$ and $27^{\text {th }}$ of April, and the $9^{\text {th }}$ of May, respectively. 


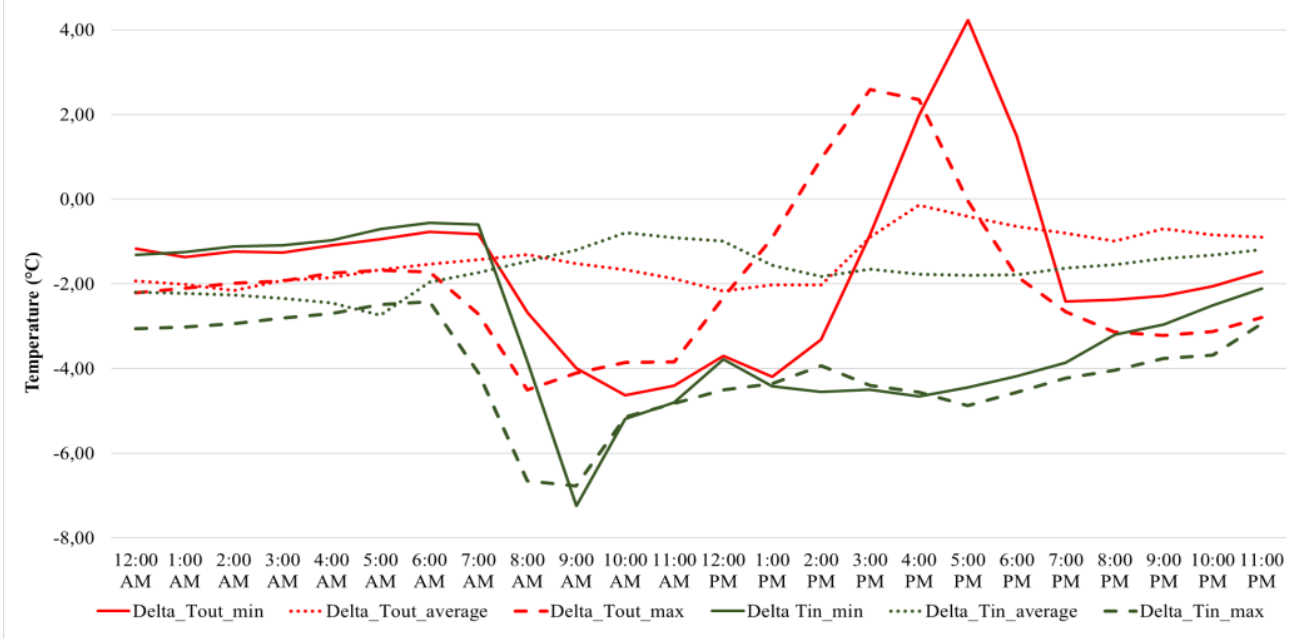

Fig. 17. Temperature differences at the ground/membrane level between the enhanced scenario and the reference case.

The temperature reduction for the top side of the membrane was observed in the morning. In particular, it was equal to $4.63^{\circ} \mathrm{C}$ (at 10 a.m.), to $2.17^{\circ} \mathrm{C}$ (at $12 \mathrm{a} . \mathrm{m}$.), and to $4.50^{\circ} \mathrm{C}$ (at 8 a.m.) on the $8^{\text {th }}$ of April, the $27^{\text {th }}$ of April, and the $9^{\text {th }}$ of May respectively.

Concerning the bottom side of the membrane, the highest $\Delta \mathrm{T}$ value was averagely as high as $7.24^{\circ} \mathrm{C}$ (at $9 \mathrm{a} . \mathrm{m}$. on the $8^{\text {th }}$ of April), while it became equal to $2.74^{\circ} \mathrm{C}$ (at $5 \mathrm{a} . \mathrm{m}$. on the $27^{\text {th }}$ of April), and to $6.77^{\circ} \mathrm{C}$ (at 9 a.m. on the $9^{\text {th }}$ of May).

Concerning the relative humidity at the ground level, it was always higher below the mulching membrane ( $\mathrm{RH}_{-} \mathrm{Cool}$ ) than in the other section (RH_Ref). The result obtained from the present study is in agreement with the findings of Sinkeviciene et al. [16] in which mulched plot exhibited higher soil moisture level compared with plots without mulch.

\section{Conclusions}

The effectiveness of a high-reflective mulching membrane in terms of soil temperature and soil moisture was investigated in this research study. Influences of this technology were determined through a monitoring campaign conducted in both a laboratory-scale prototype (preliminary) and a small-scale experimental field in Perugia. For the purpose of this study, three representative days of the environmental monitoring campaign (i.e. showing the minimum air temperature- $8^{\text {th }}$ of April, the maximum air temperature- $9^{\text {th }}$ of May, and the mean air temperature- $27^{\text {th }}$ of April, respectively) were selected in order to evaluate the effects of the mulching membrane in different weather conditions.

The main findings are summarized in the following bullet points:

- The temperature fluctuations throughout the day were lower below the mulching membrane;

- The soil temperature values (throughout all the investigated depths) were lower in the configuration enhanced with the mulching membrane than in the section without that in all three selected days. The highest reduction in soil temperature was equal to $8.95^{\circ} \mathrm{C}$ (at 4 p.m.) at $0.15 \mathrm{~m}$ below the ground surface thanks to the mulching membrane on the $9^{\text {th }}$ of May; 
-Mulching membrane surface temperature at the top side showed higher temperature fluctuations than temperature at ground level in the unmulched soil. Nonetheless, the highest $\Delta \mathrm{T}$ value was equal to $4.63^{\circ} \mathrm{C}$ (at 10 a.m.) on the $8^{\text {th }}$ of April;

- The membrane surface temperature at the bottom side showed always the lowest values in comparison with the reference case's ground surface for all the representative days. The highest $\Delta \mathrm{T}$ value was averagely as high as $7.24^{\circ} \mathrm{C}$ (at $9 \mathrm{a} . \mathrm{m}$. on the $8^{\text {th }}$ of April);

-The mulching membrane was found capable of reducing relative humidity variation throughout the day if compared to the reference case.

Further analyses could be carried out to extend and integrate results presented in this research study and to evaluate the effects of the high-reflective mulching membrane on the plants' growing cycle, and on the nutritional and organoleptic properties of food crops cultivated, in order to achieve a sustainable and healthy diet.

\section{References}

1. M. Santamouris, C. Cartalis, A. Synnefa, D. Kolokotsa, Energy Build. 98, 119-124 (2015).

2. United Nations, Department of Economic and Social Affairs, Population Division (2014). World Urbanization Prospects: The 2014 Revision, Highlights (ST/ESA/SER.A/352).

3. I. Lima, V. Scalco, R. Lamberts, Energy Build. 182, 30-44 (2019).

4. L. Lin, E. Ge, X. Liu, W. Liao, M. Luo, Atmos. Res. 210, 123-132 (2018).

5. H. Akbari, D. Kolokotsa, Energy Build. 133, 834-842 (2016).

6. F. Cotana, F. Rossi, M. Filipponi, V. Coccia, A.L. Pisello, E. Bonamente, A. Petrozzi, G. Cavalaglio, Appl. Energy 130, 641-647 (2014).

7. M. Manni, A. Petrozzi, V. Coccia, A. Nicolini, F. Cotana, J. Build. Eng. 31, 101340 (2020).

8. M. Manni, G. Lobaccaro, F. Goia, A. Nicolini, Sol. Energy 176, 194-210 (2018).

9. F. Rossi, B. Castellani, A. Presciutti, E. Morini, E. Anderini, M. Filipponi, A. Nicolini, Energy Build. 126, 340-352 (2016).

10. A. Synnefa, M. Santamouris, K. Apostolakis, Sol. Energy 81, 488-497 (2007).

11. H. Akbari, R. Levinson, L. Rainer, Energy Build. 37, 1007-1016 (2005).

12. S.R. Mendonça, M.C.R. Ávila, R.G. Vital, Z.R. Evangelista, N. de Carvalho Pontes, A. dos Reis Nascimento, Sci. Hortic. 275, 109657 (2021). 13. E. Kosterna, Folia Hort. 26/2, 91-101 (2014).

14. M.N. Tswanya, J.O. Olaniyi, T.T. Atanda, Curr. Trends Bionmedical Eng. \& Biosci. 5(3), 52-60 (2017).

15. M. Manni, A. Di Giuseppe, A. Petrozzi, A. Nicolini, F. Rossi, F. Cotana, E3S Web Conferences 197, 08012 (2020), $75^{\circ}$ National ATI Congress.

16. A. Sinkeviciene, D. Jodaugiene, R. Pupaliene, M. Urboniene, Agron. Res. 7(1), 48549 (2009).

17. D.A.N. Majumder, S.C. Nath, M.A. Kabir, S. Majumder, N. Usantara Biosci. 8, 123 127 (2016).

18. X. Zhang, S. You, Y. Tian, J. Li, Sci. Hortic. 249, 38-48 (2019).

19. M.W. Schonbeck and G.K. Evanylo, J. Sustain. Agric. 13(1), 55-81 (1998).

20. P. Pramanik, K.K. Bandyopadhyay, D. Bhanduri, R.B. Acharyyal, P. Aggarwal, IJAEB 8, 645-658 (2015). 